Supporting Information

\title{
Multifunctional Textured Surfaces with Enhanced \\ Friction and Hydrophobic Behaviors Produced by
}

\section{Fiber De-bonding and Pullout}

Reza Rizvi, Ali Anwer, Hani Naguib*, Geoff Fernie and Tilak Dutta

*Corresponding Author - Prof. H. Naguib (naguib@,mie.utoronto.ca)

Dr. R. Rizvi, A. Anwer, Prof. H. Naguib

Department of Mechanical and Industrial Engineering

Department of Materials Science and Engineering

University of Toronto

5 Kings College Cr., Toronto, M5S3G8, Canada

Prof. H. Naguib, Dr. G. Fernie, Dr. T. Dutta

Institute of Biomaterials and Biomedical Engineering

University of Toronto

164 College St., Toronto, M5S3G9, Canada

Dr. R. Rizvi, Prof. G. Fernie, Dr. T. Dutta

Toronto Rehabilitation Institute

University Health Network

550 University Ave., Toronto, M5G2A2, Canada 


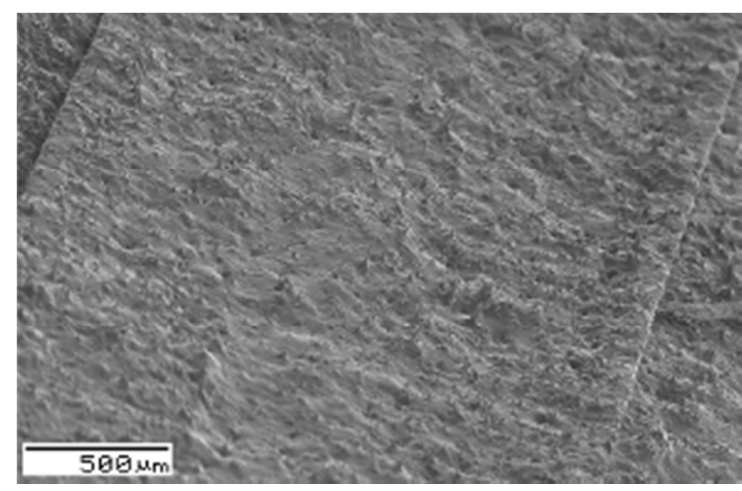

(a)

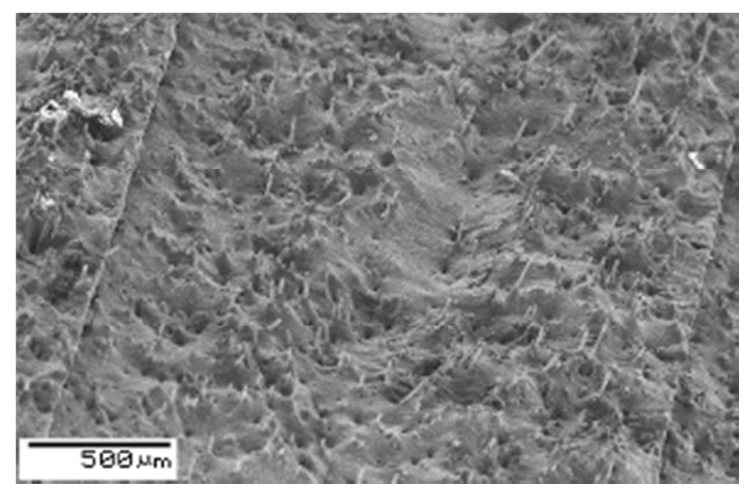

(b)

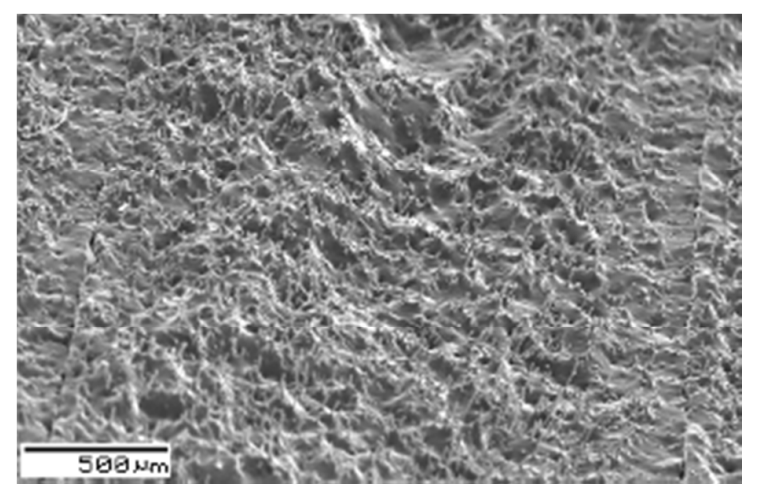

(c)
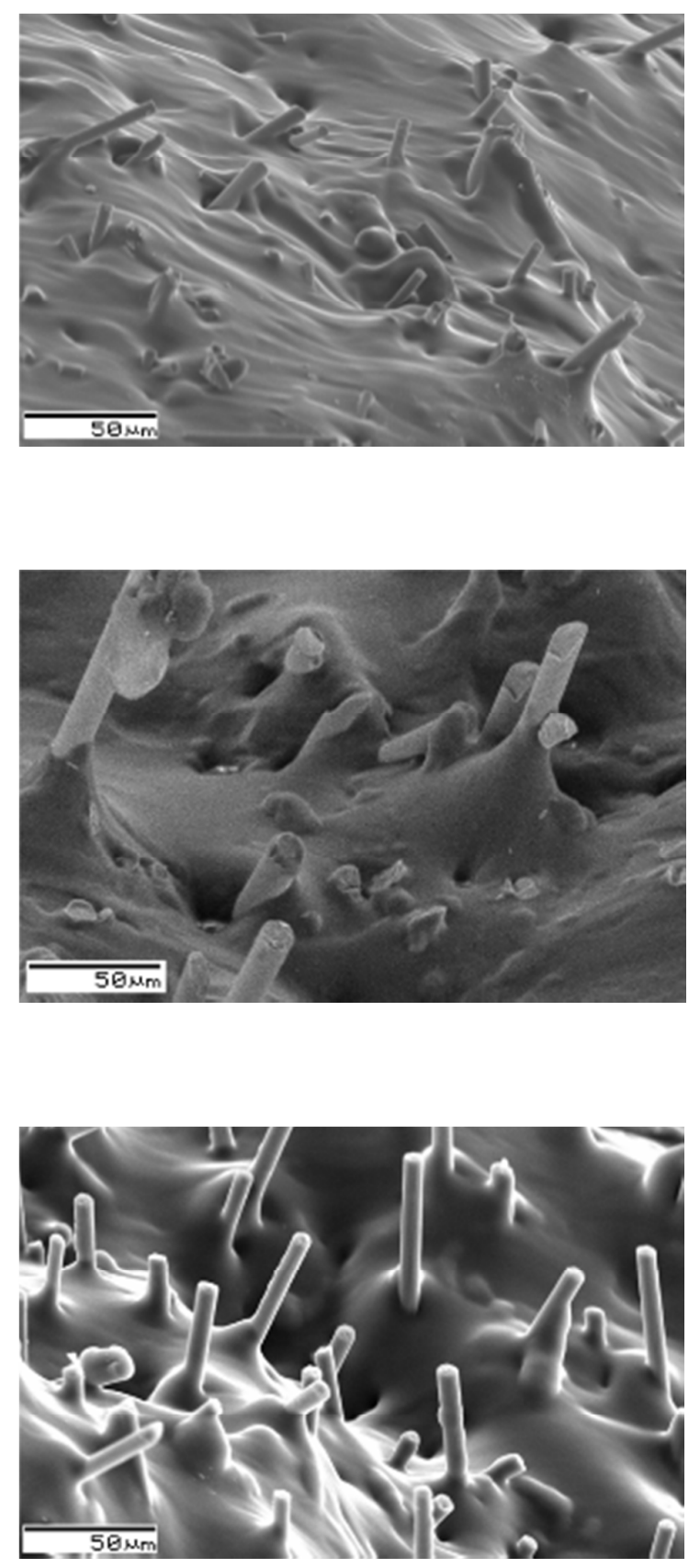

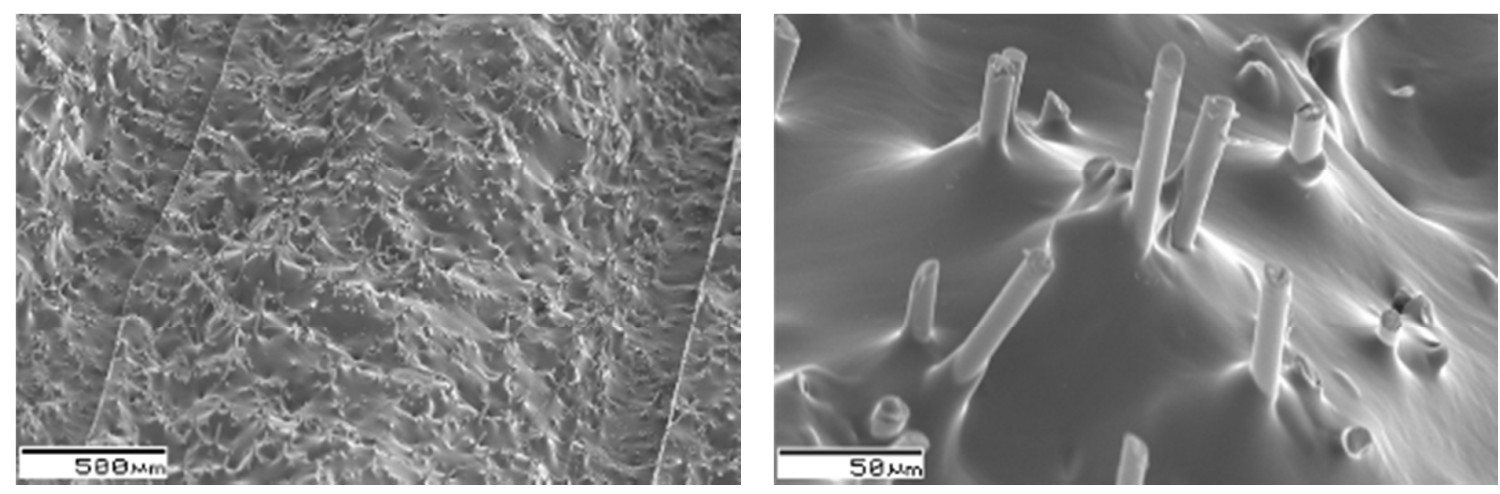

(d)
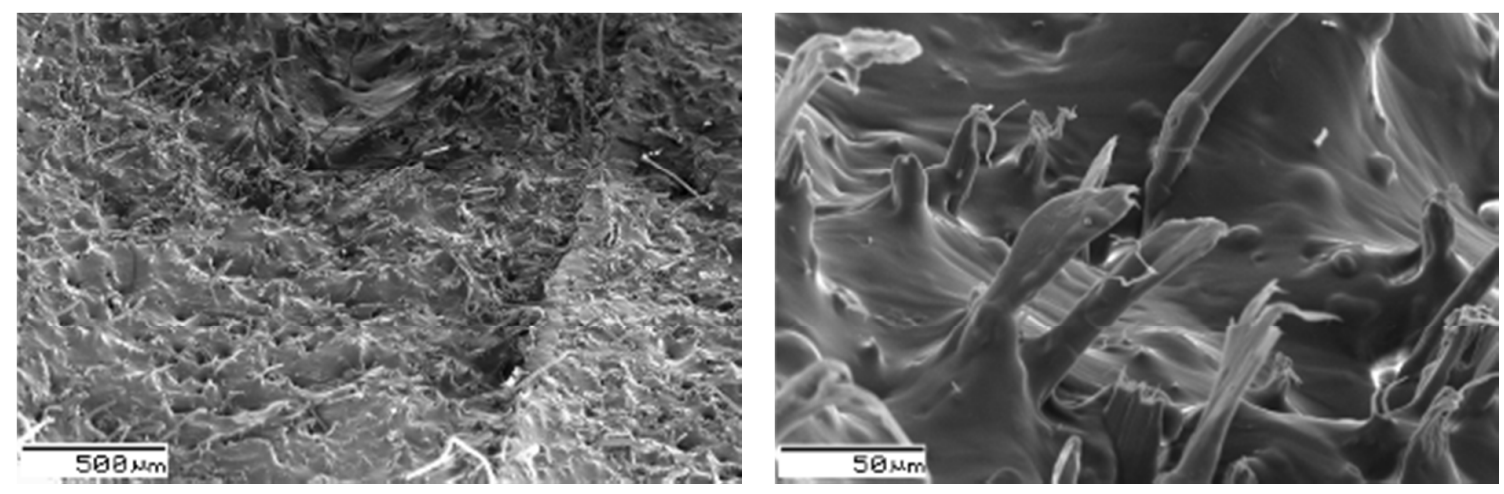

(e)
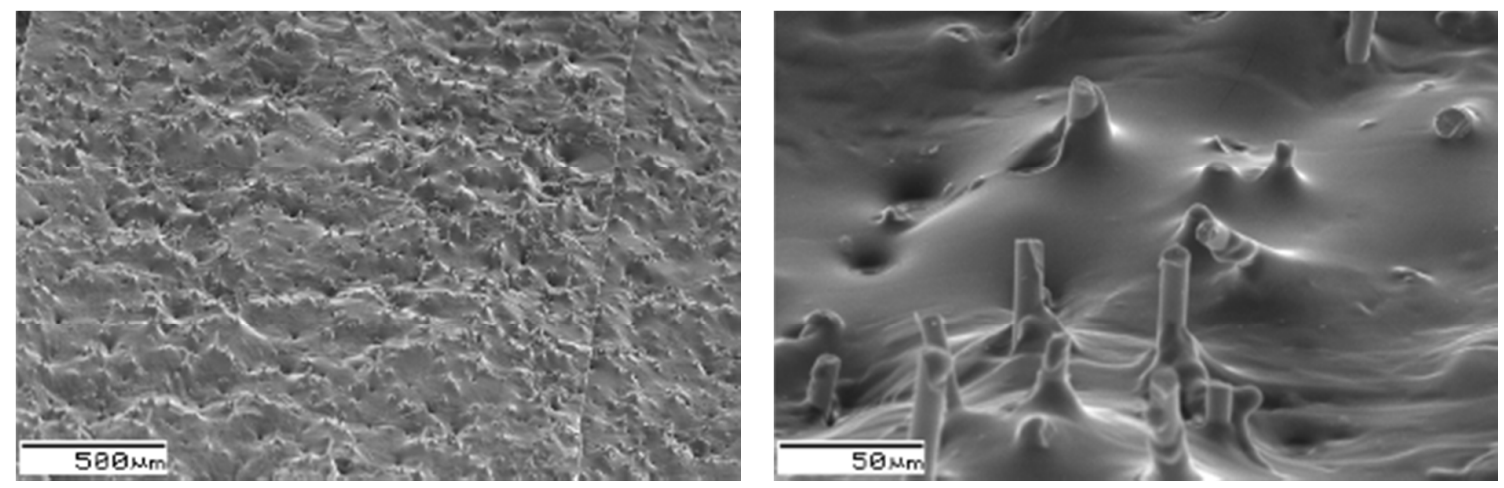

(f) 

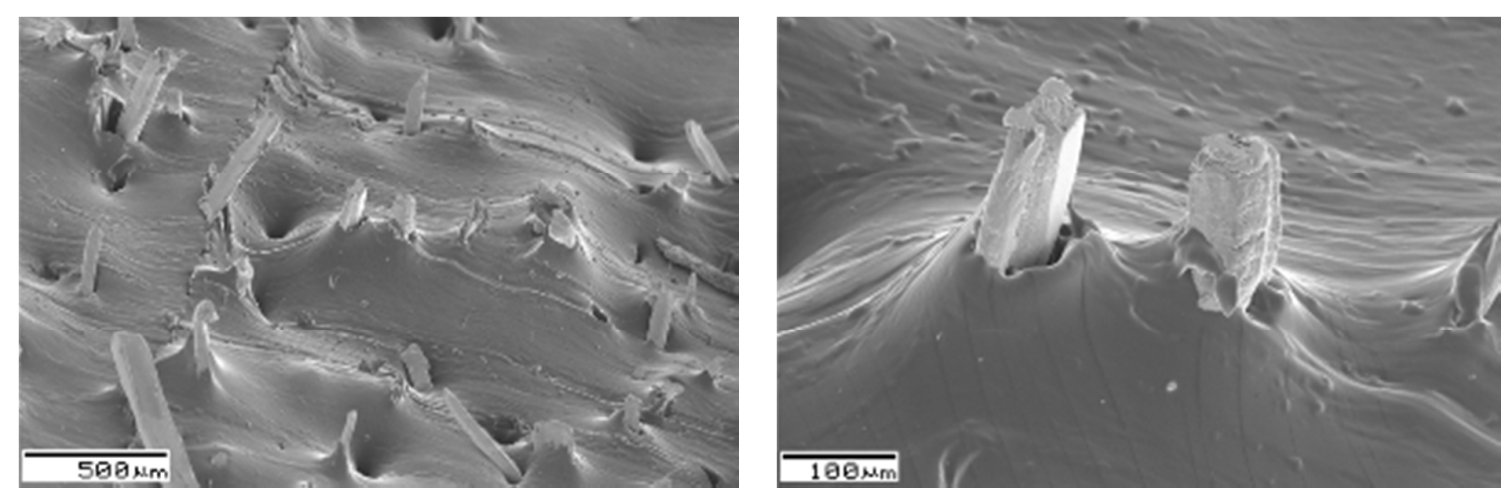

$(\mathrm{g})$

Figure S1. Low and high magnification SEM images of textured composite surfaces containing various fiber types made possible due to fiber de-bonding and pull-out during the cutting and re-arranging process. Intermediate magnifications are available in Figure 2 in text. 


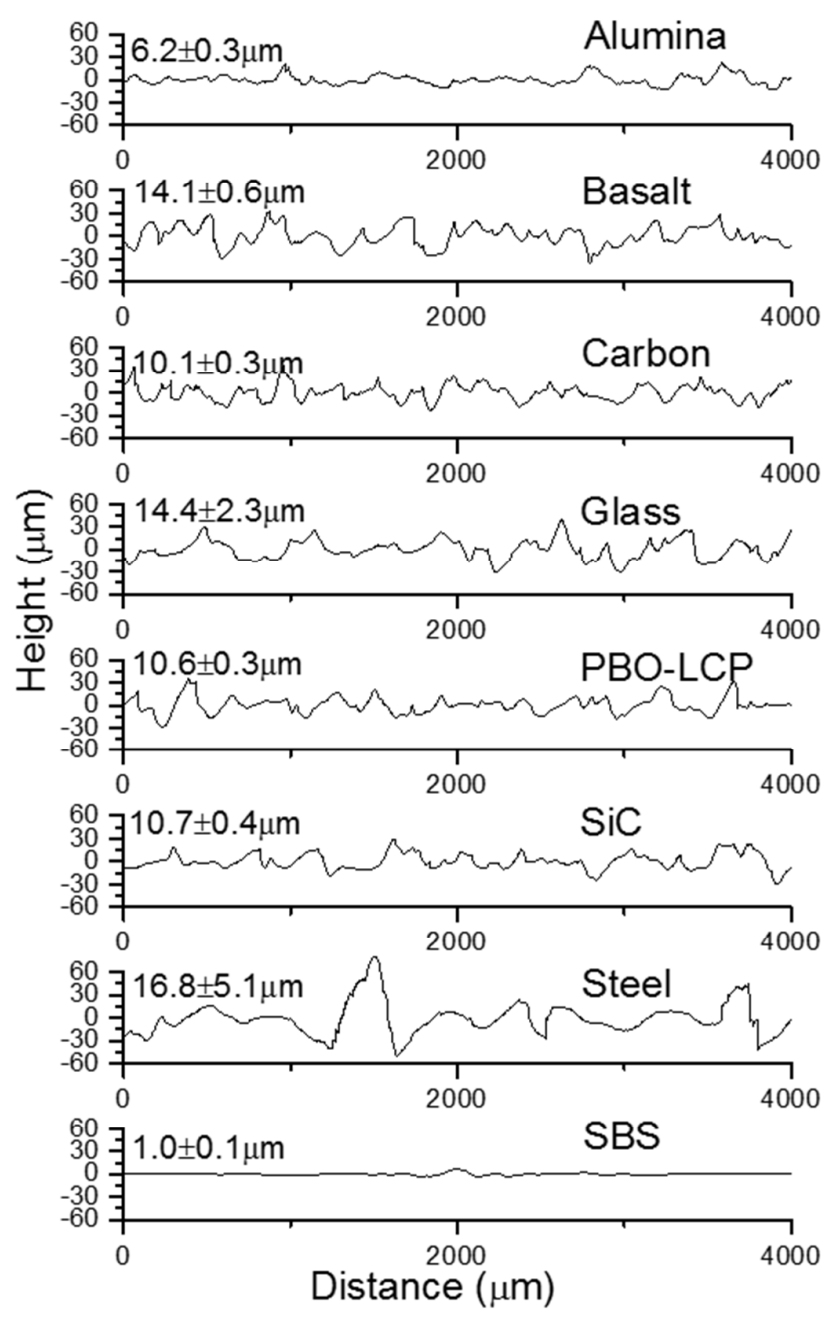

Figure S2. Typical linear surface scan profiles for various fiber types, along with their average $(\mathrm{N}=3)$ values and the standard deviation. 


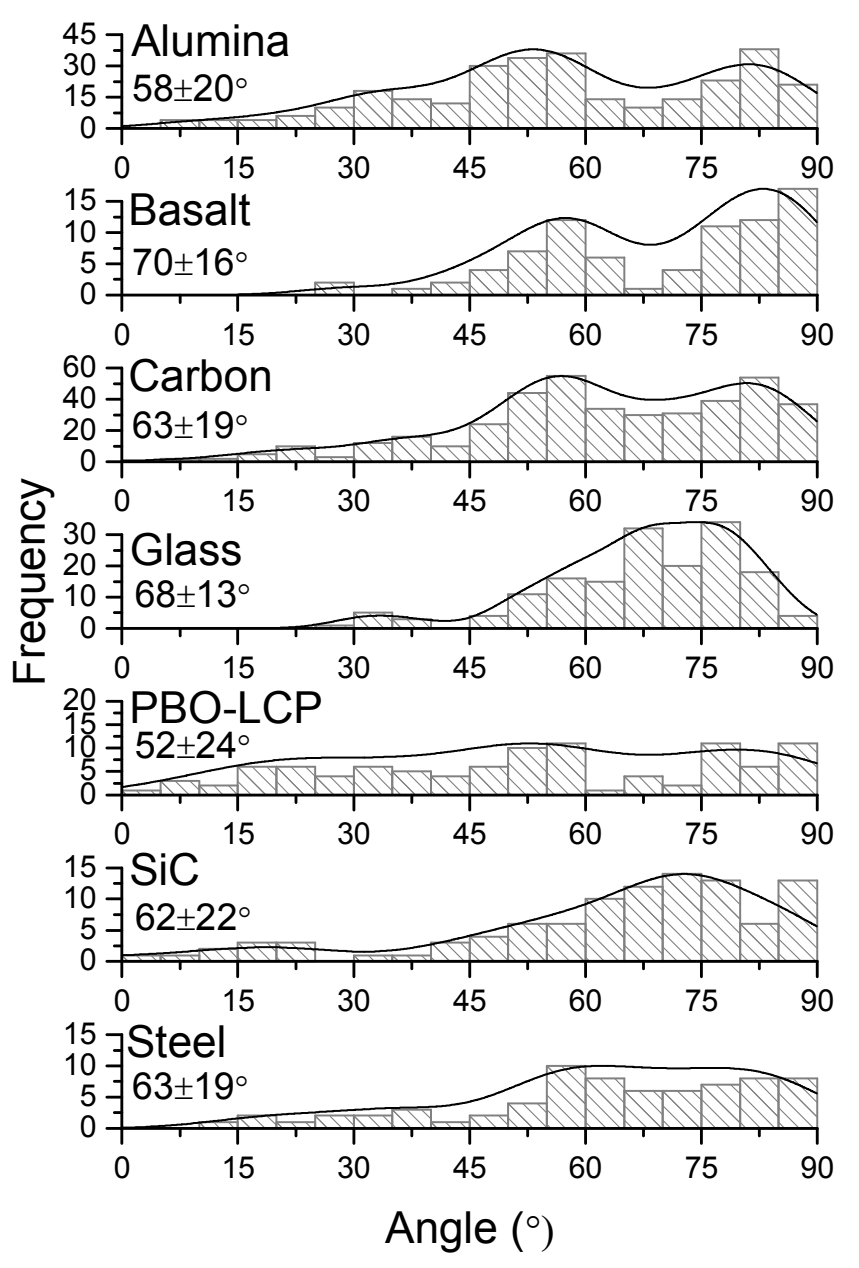

Figure S3. Fiber pullout angle distribution for various fiber types, along with their average values and the standard deviation. Solid line depicts the smooth kernel fit of the available data. 


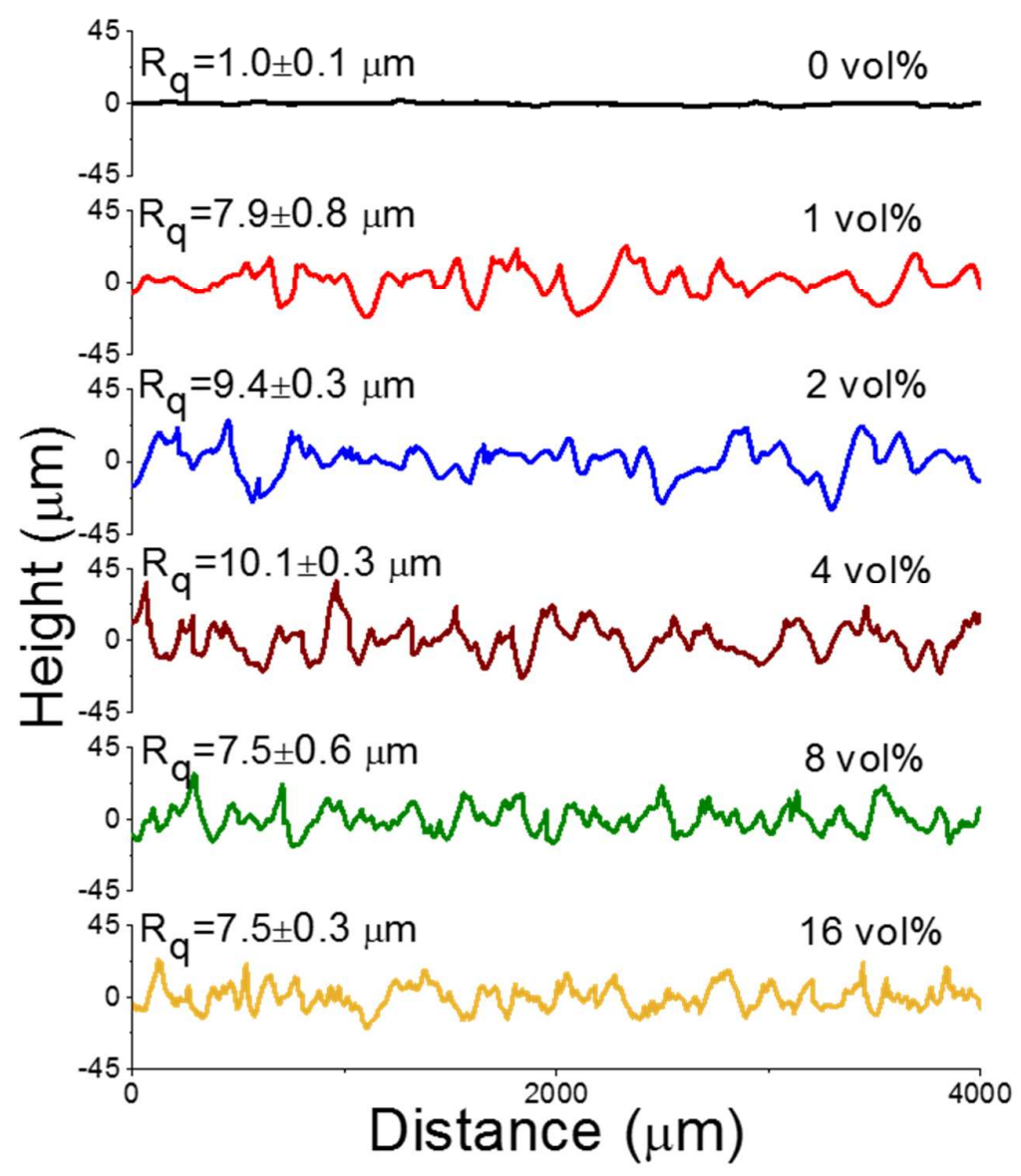

Figure S4. Typical linear surface scan profiles for textured composites of SBS containing various amounts of Carbon Fiber $(\mathrm{CF})$, along with their average $(\mathrm{N}=3)$ values and the standard deviation. 


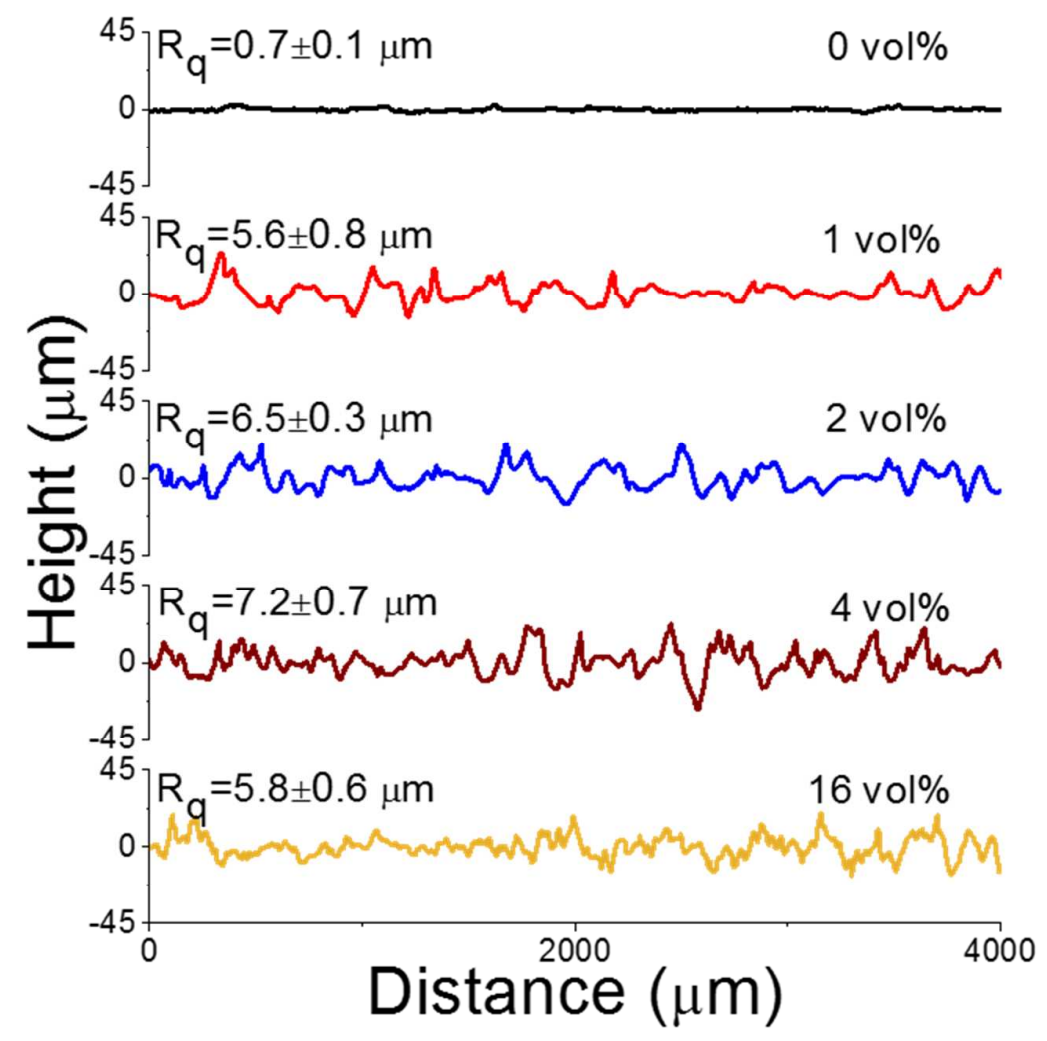

Figure S5. Typical linear surface scan profiles for textured composites of TPU containing various amounts of Carbon Fiber $(\mathrm{CF})$, along with their average $(\mathrm{N}=3)$ values and the standard deviation. 

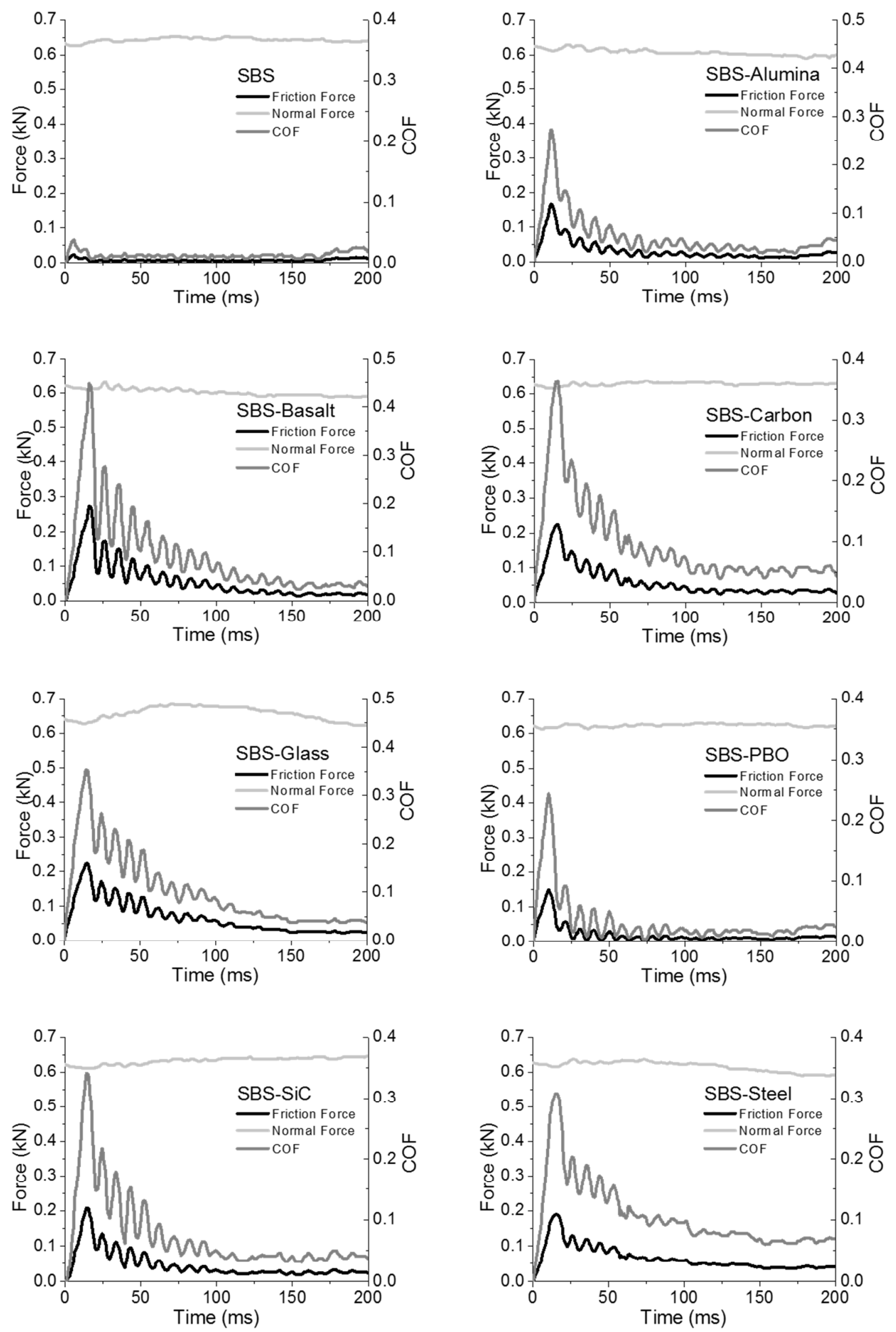

Figure S6. First run friction traces for various surface textured composites on wet ice. 


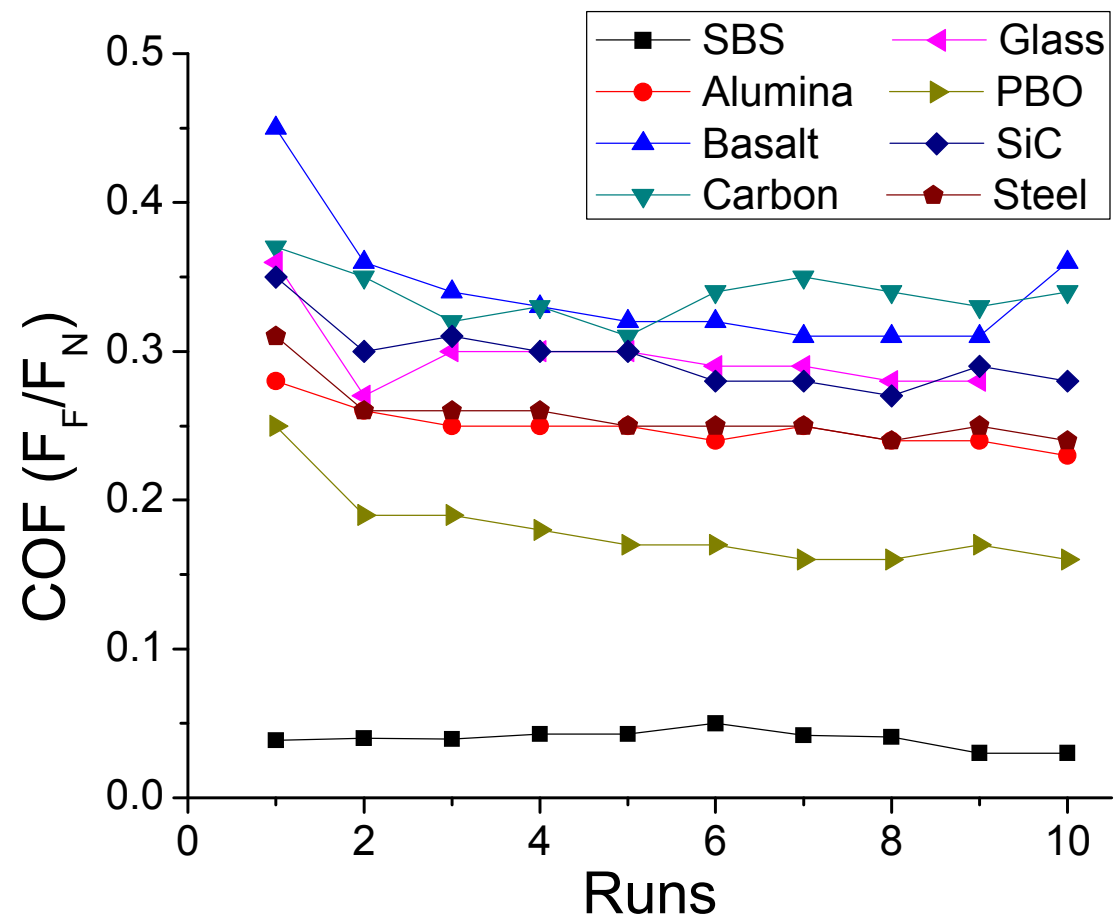

Figure S7. Repeated coefficients of friction (COF) for various surface textured composites on wet ice. 


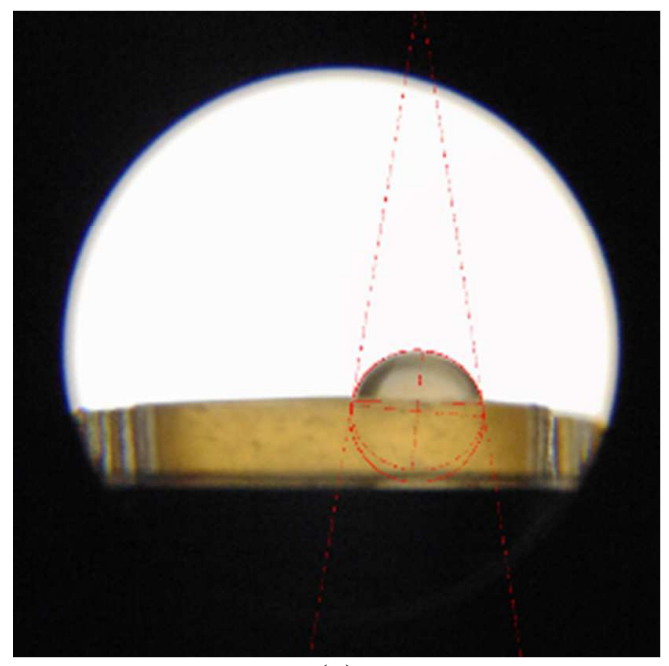

(a)

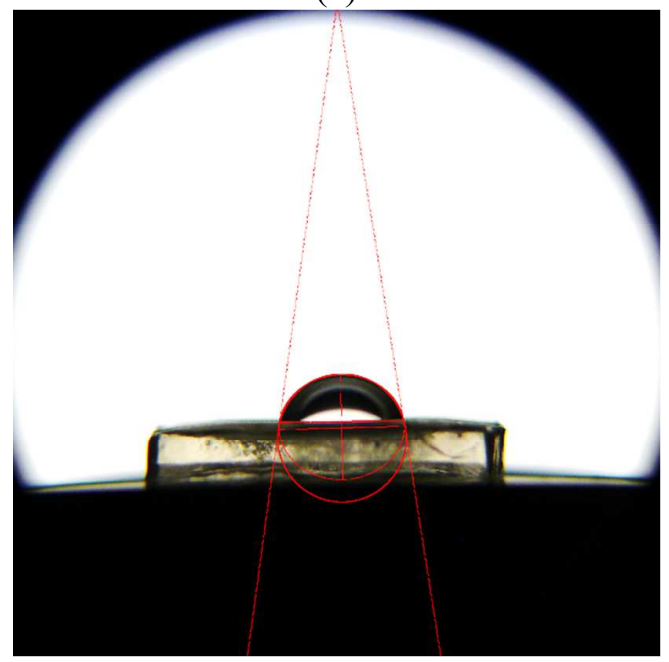

(c)

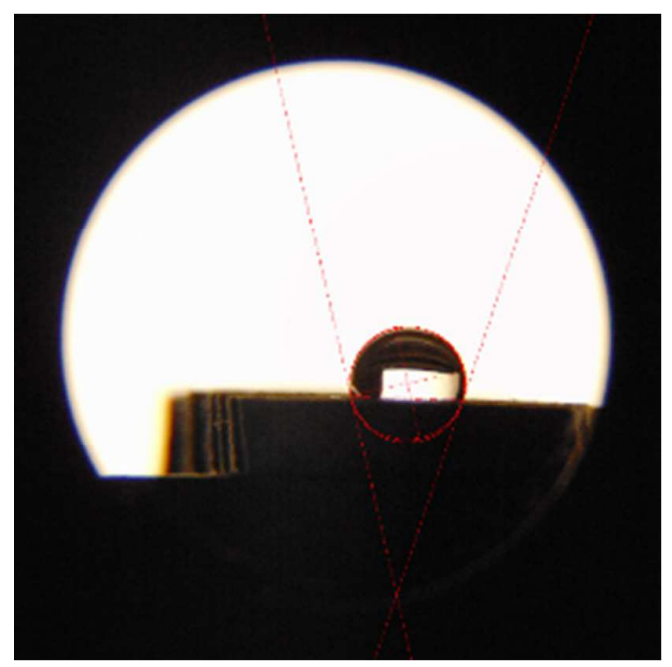

(b)

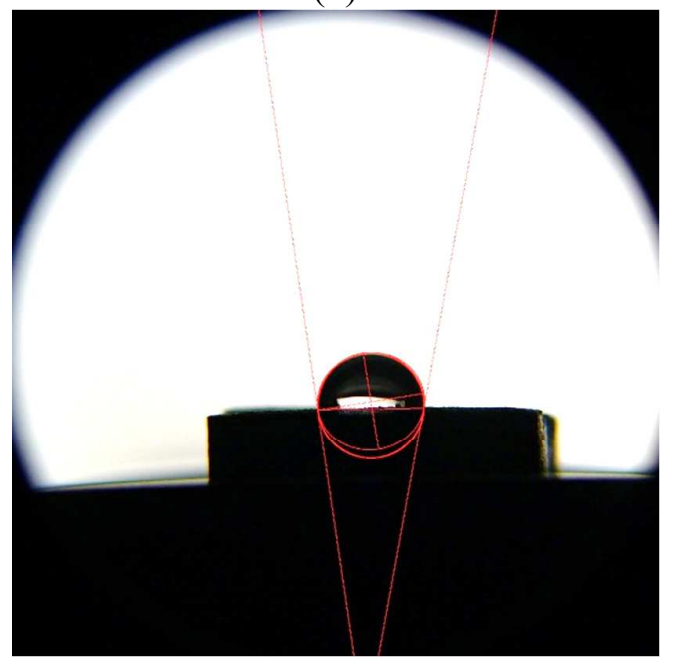

(d)

Figure S8. Water droplet images showing the droplet shaped estimated (red) by a fitting an eclipse through two baseline points and three liquid-air boundary edge points for (a) SBS, (b) SBS-16 vol\% CF, (c) TPU, (d) TPU-16 vol\% CF. 


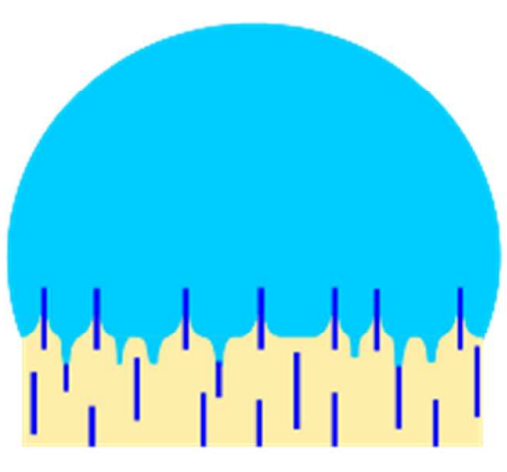

2-phase heterogeneous surface Fiber \& Matrix

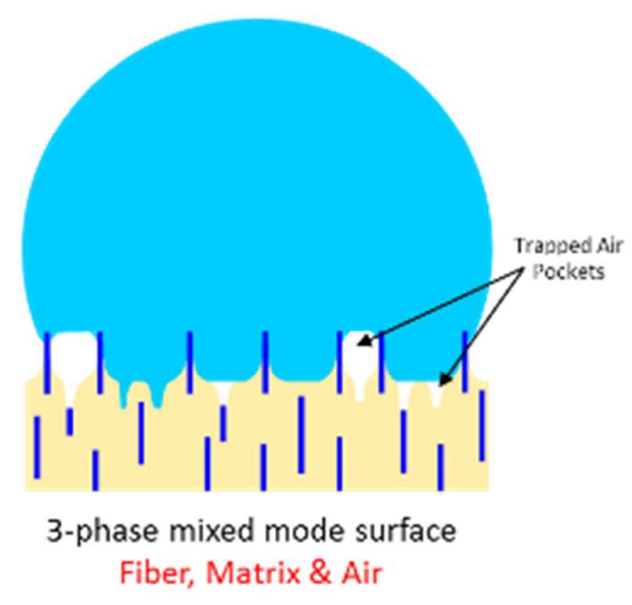

Figure S9. Schematic illustrating the two and three phase Cassie heterogenous surface modes possible for wetting of the textured composites. 


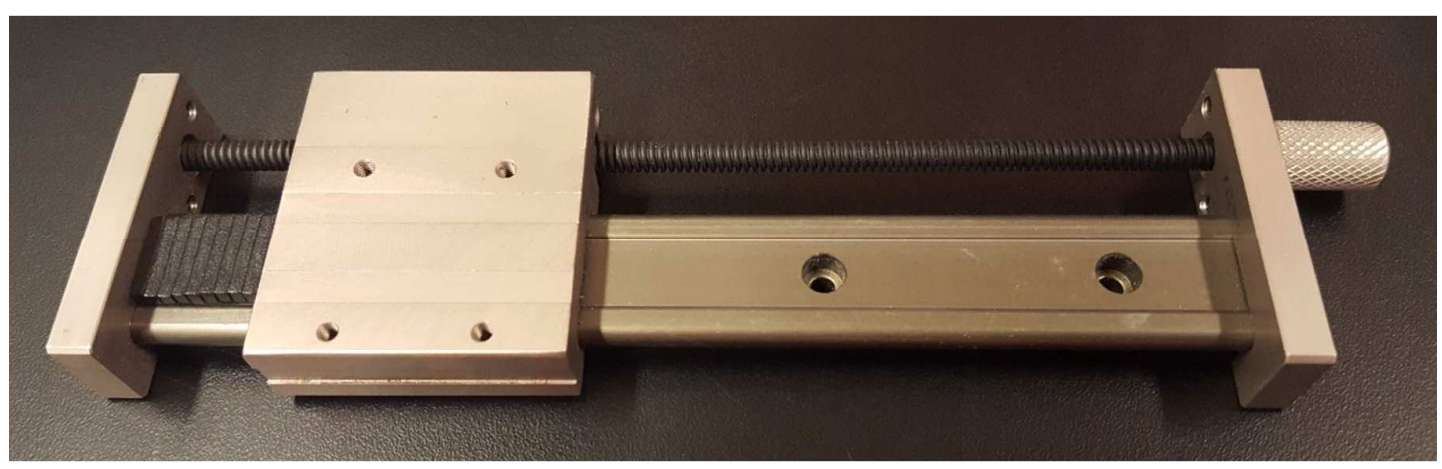

Figure S10. Rig used to hold the cut slices together during the refusing process.

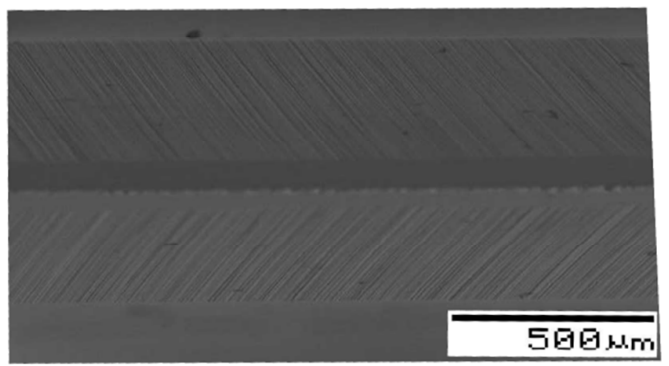

(a)

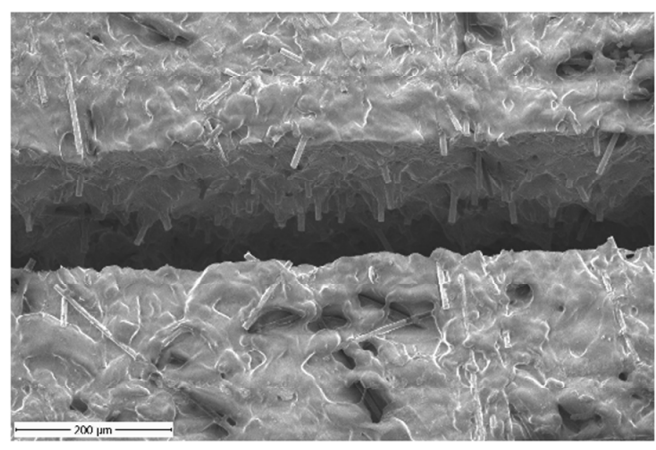

(b)

Figure S11 a) SEM image of blade tip used for cutting composite, b) SEM image of partial slit made in composite surface showing exposed fibers on either side of cut surface 


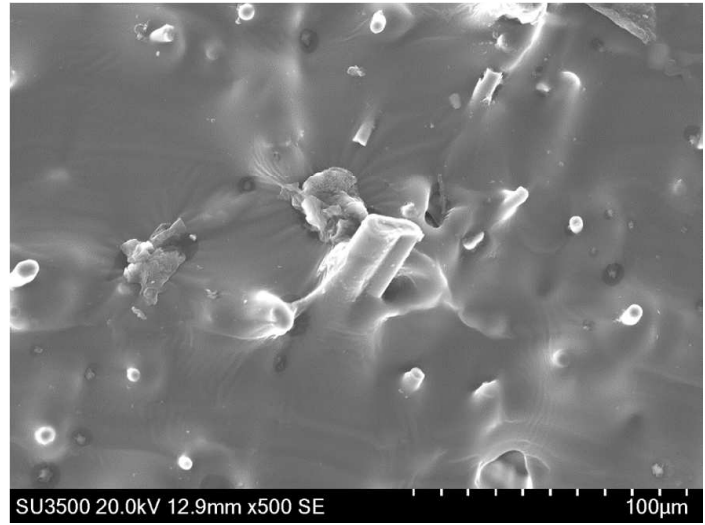

(a)

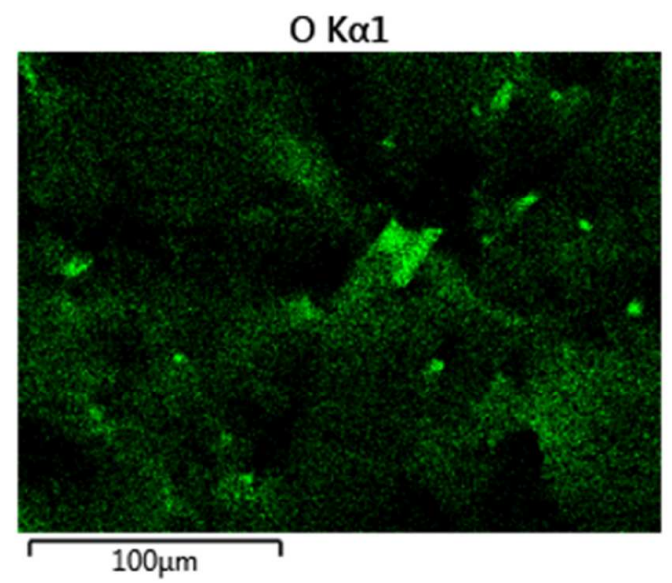

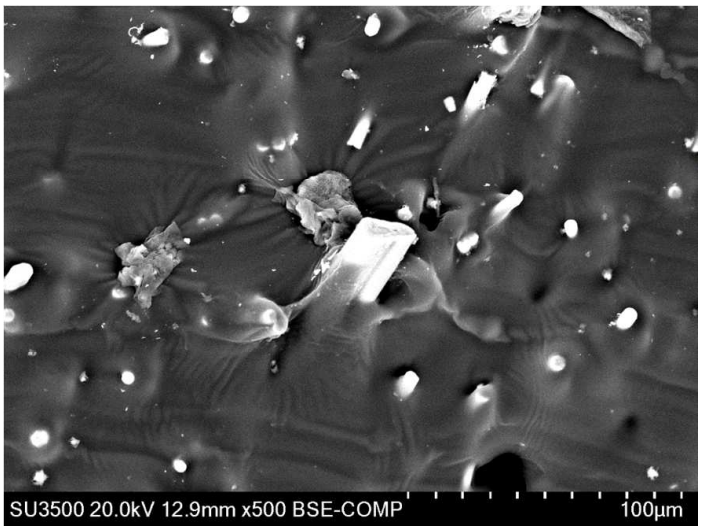

(b)

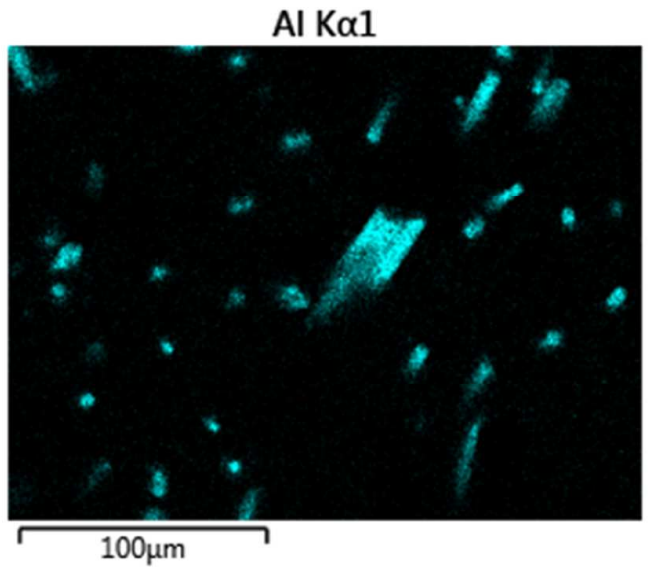

(c)

Figure S12 a) Secondary Electron, b) Back Scatter Electron and c) EDX images of AluminaTPU composite showing presence of diol groups in TPU and fiber wetting behavior evident from the wetting effect of TPU matrix onto Alumina fiber. 